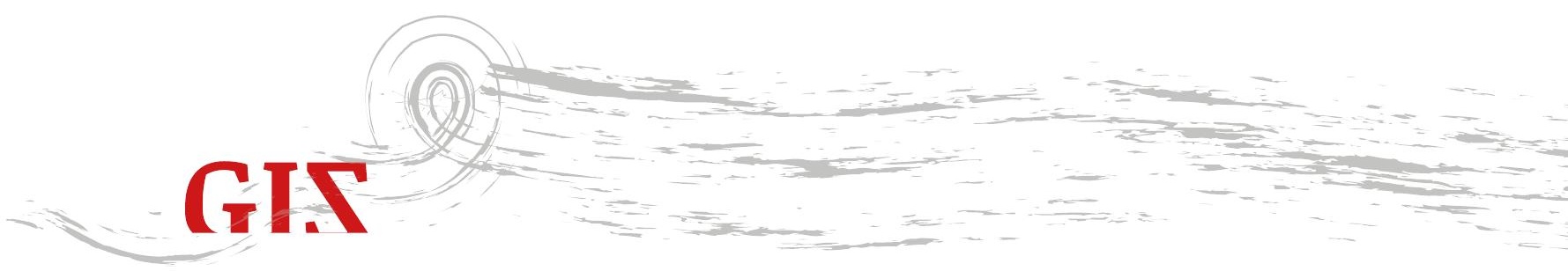

Laboratório de Antropologia Visual, RENATO ATHIAS Universidade Federal de Pernambuco, SARAPÓ PANKARARU

Recife, Pernambuco, Brasil.

\title{
AS FORÇAS ENCANTADAS: DANÇA, FESTA E RITUAL ENTRE OS PANKARARU
}
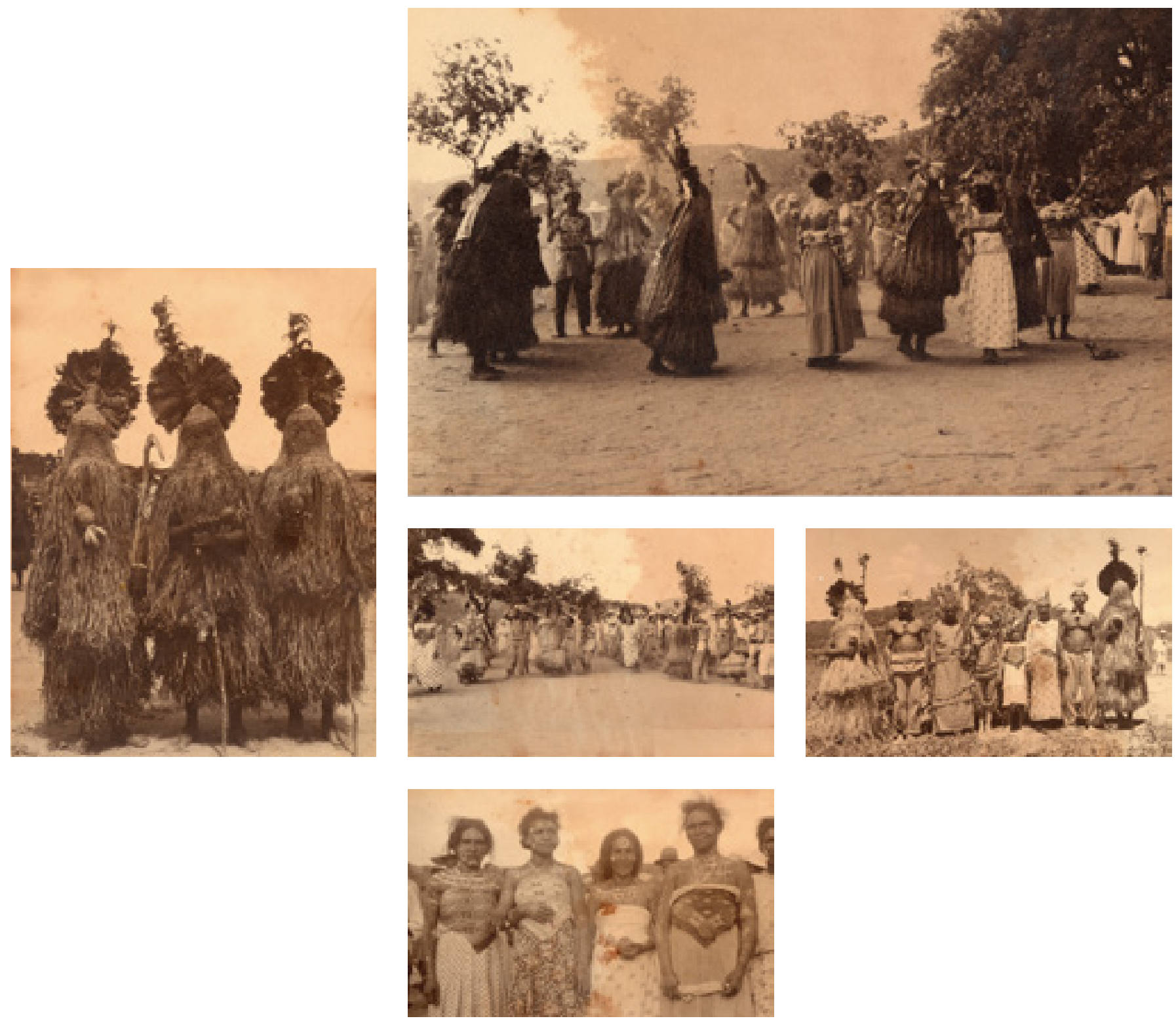


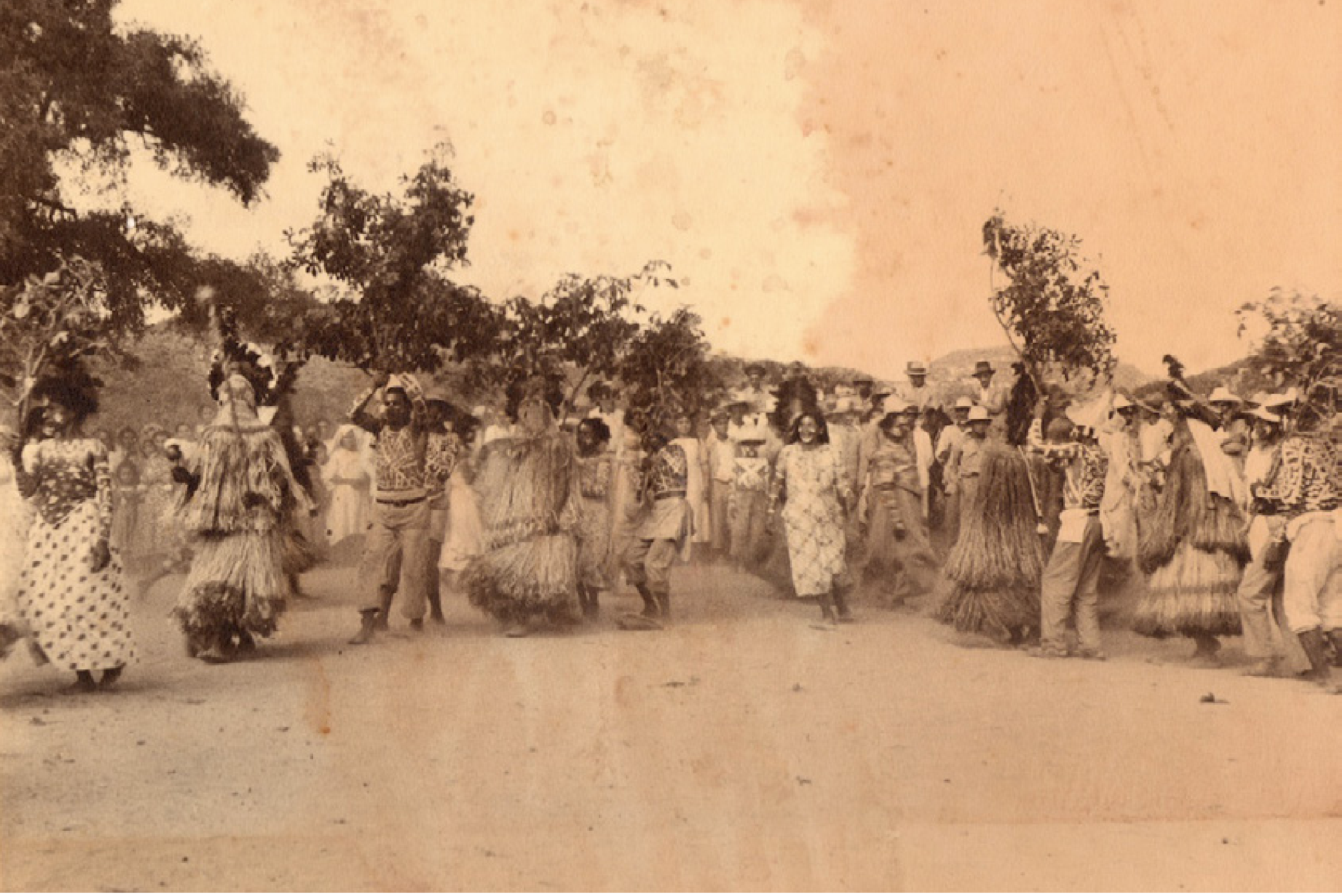




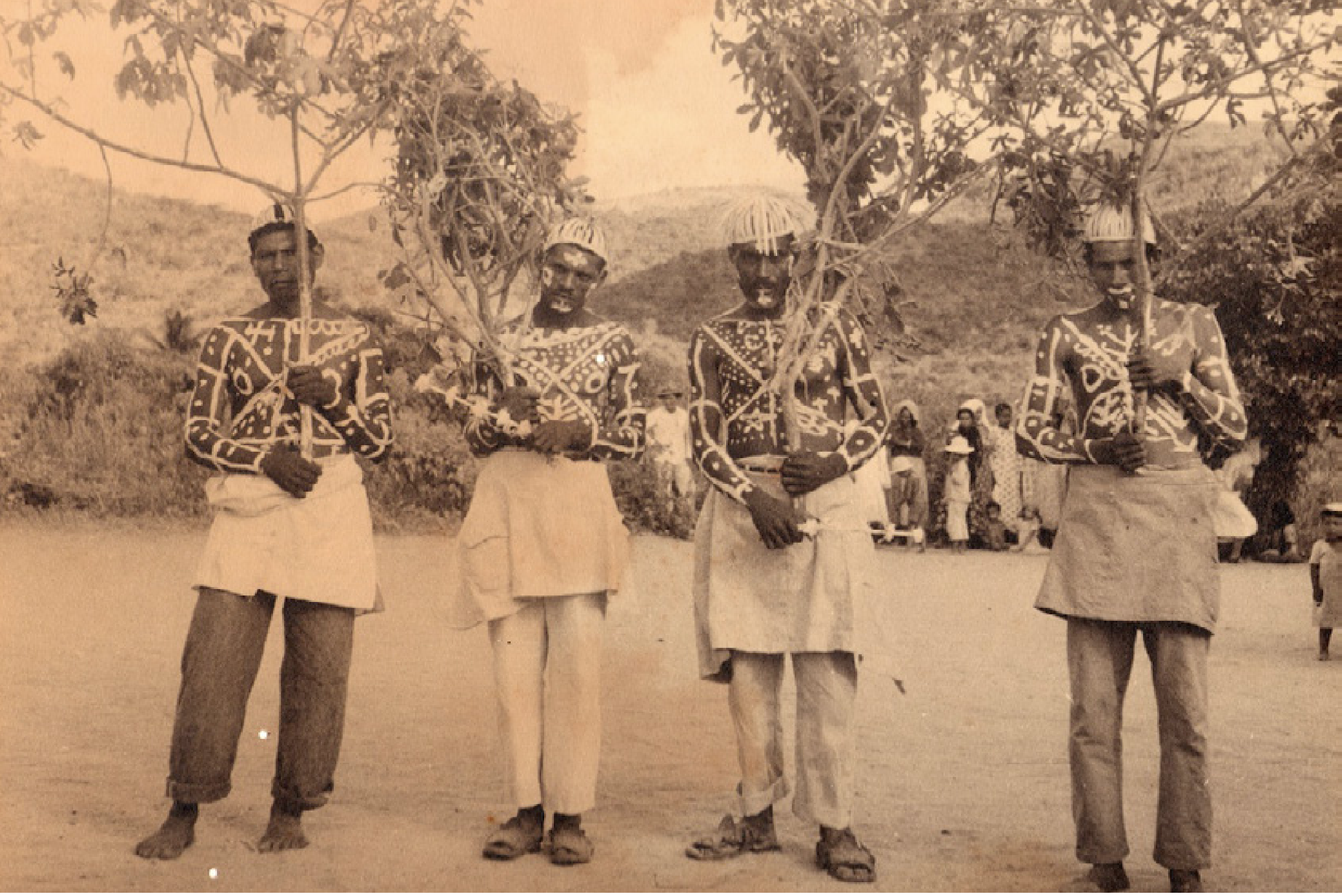




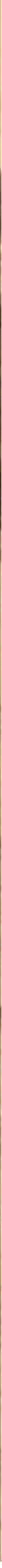




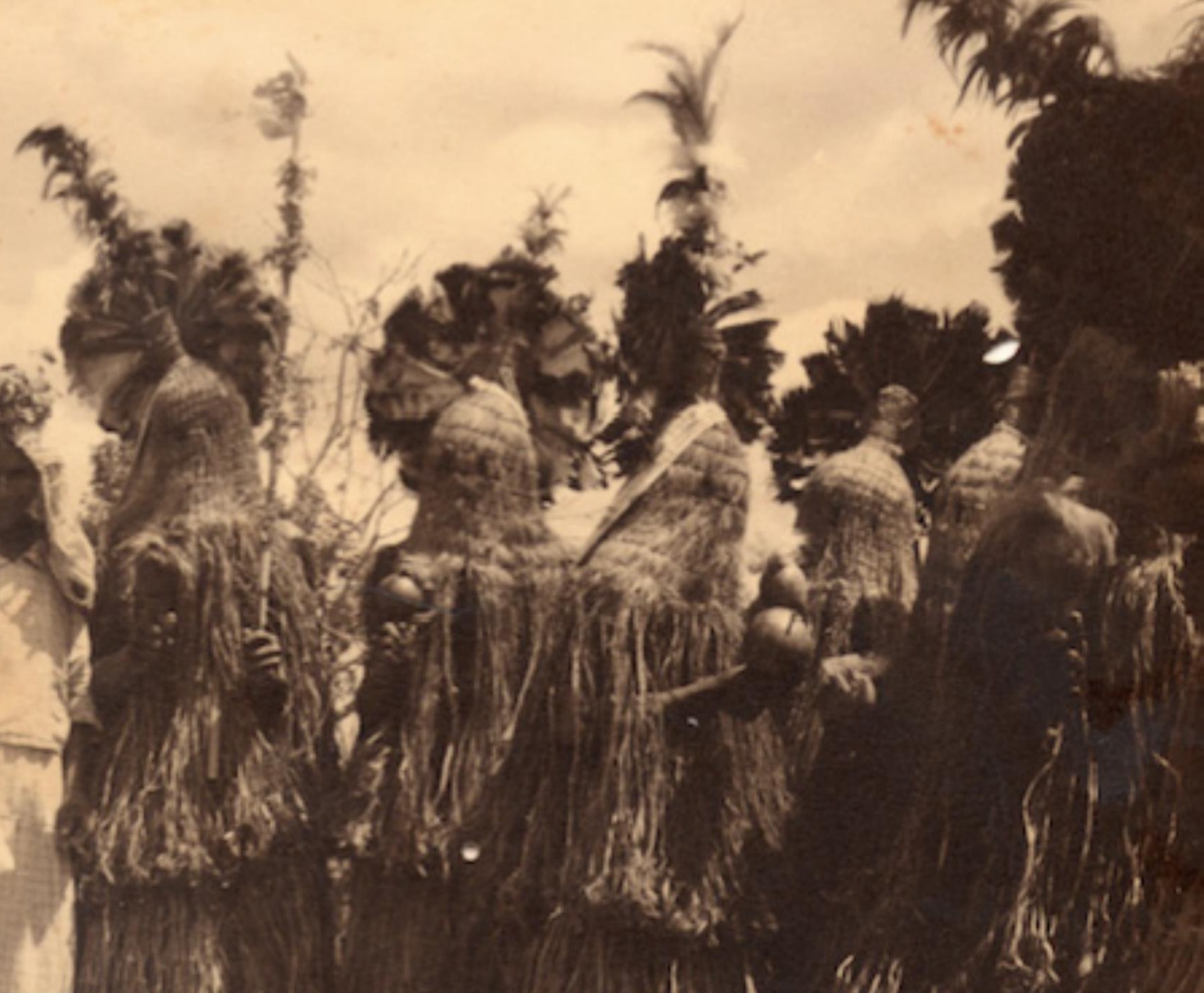




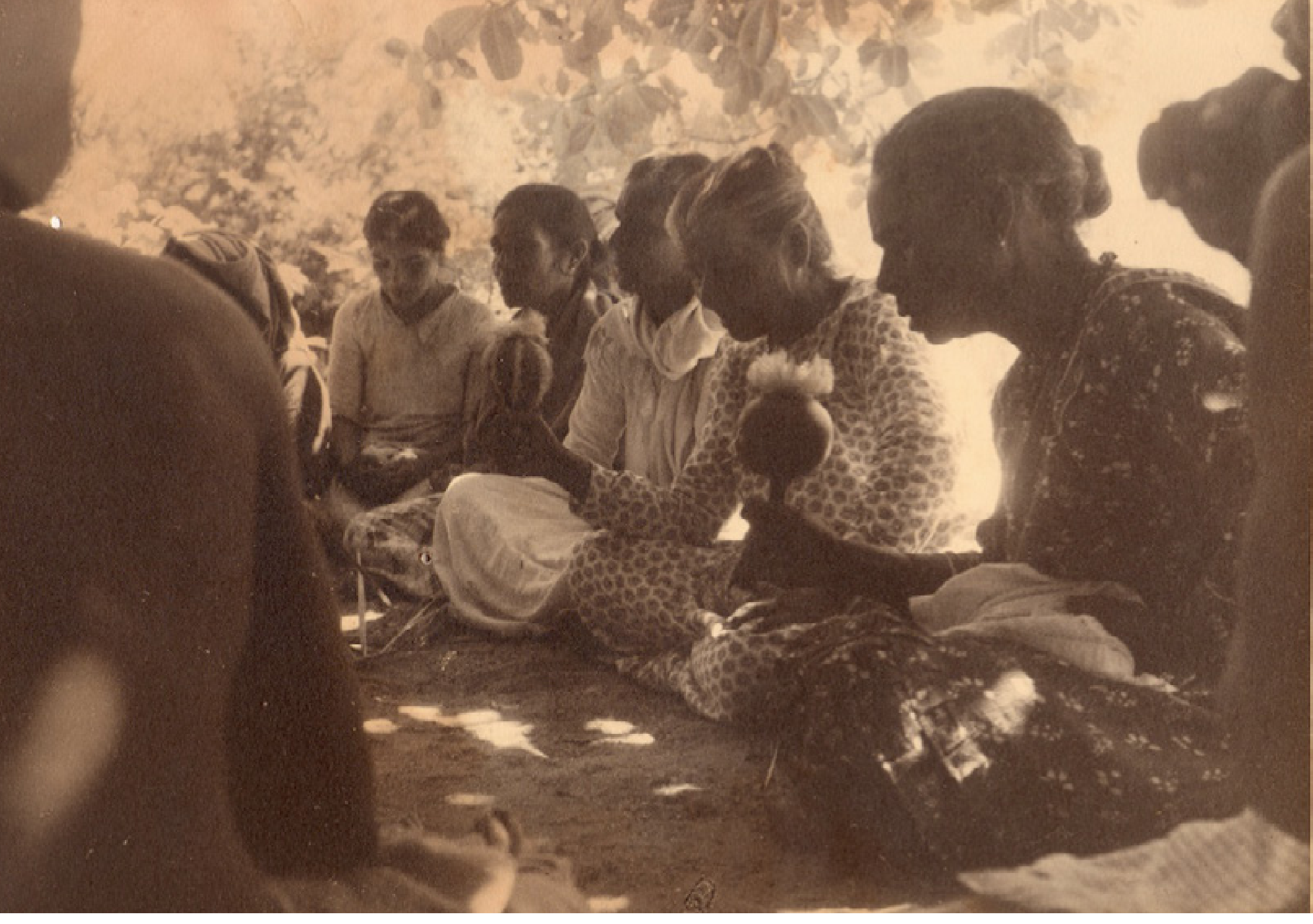




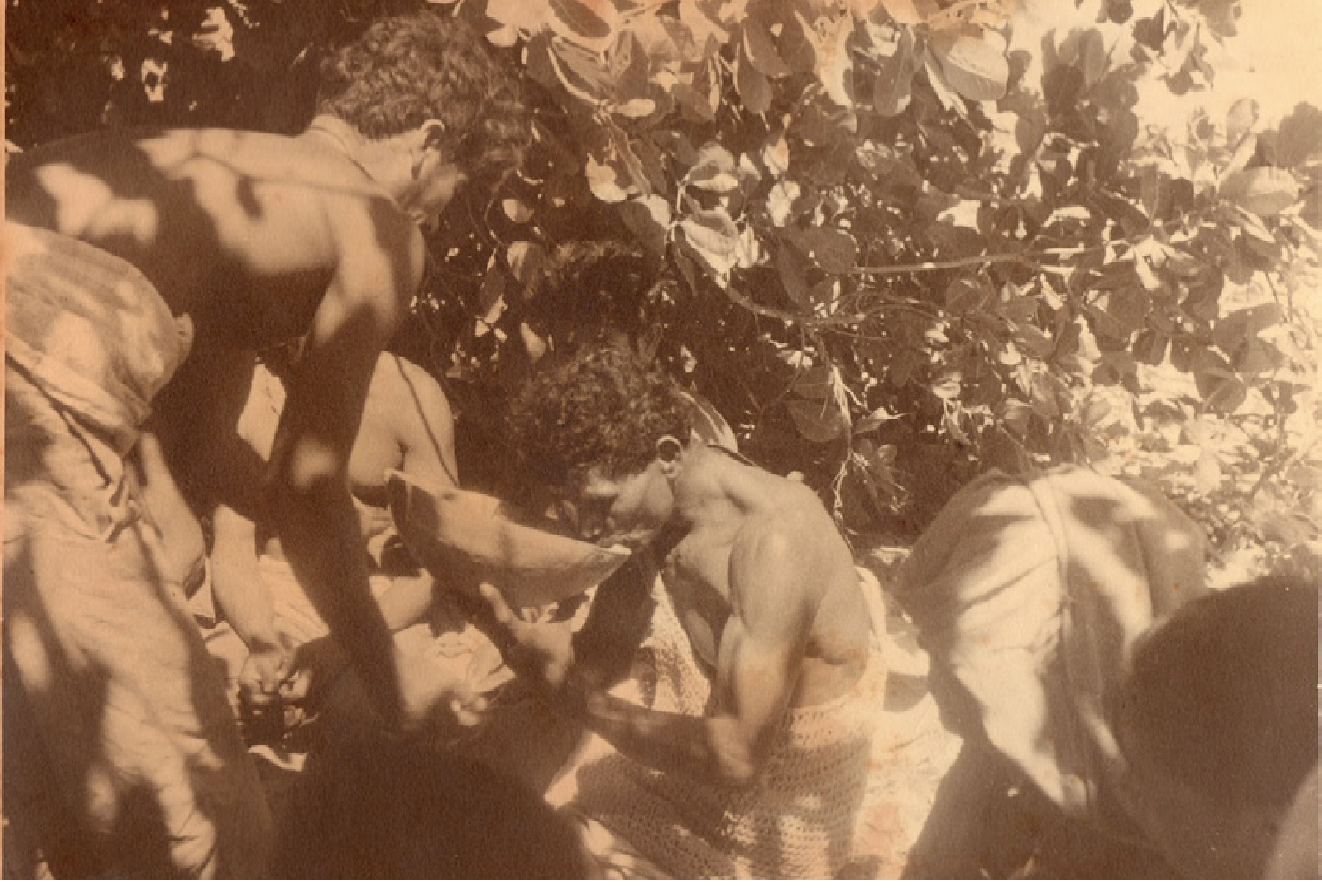




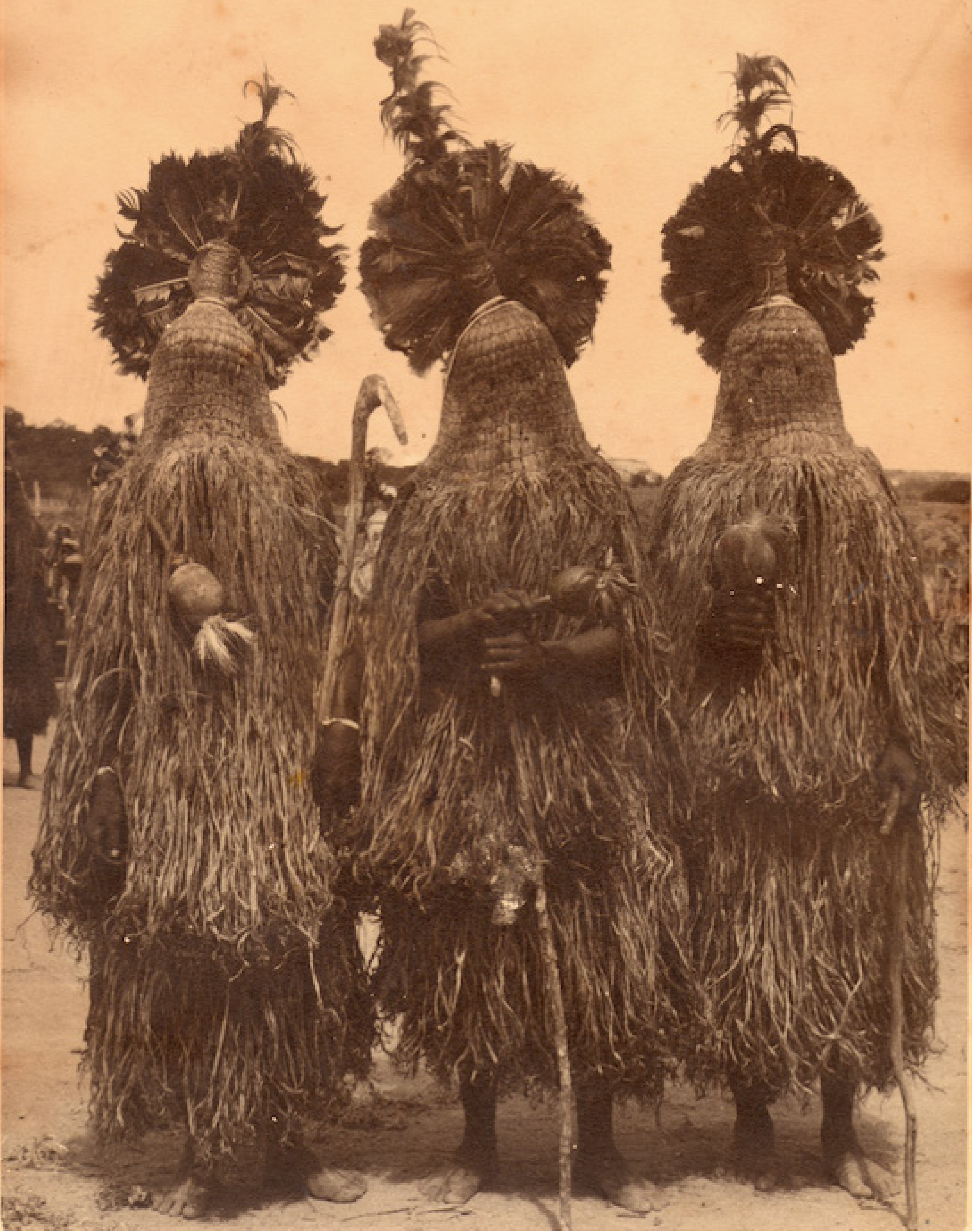




\section{RENATO ATHIAS \\ SARAPÓ PANKARARU}

\section{AS FORÇAS ENCANTADAS: DANÇA, FESTA E RITUAL ENTRE OS PANKARARU}

"As forças encantadas: dança, festa e ritual entre os Pankararu" é um ensaio fotográfico elaborado a partir do acervo de imagens de Carlos Estevão de Oliveira, do Museu do Estado de Pernambuco, no âmbito do projeto intitulado: "Povos Indígenas de Pernambuco: Memória, Documentação e Pesquisas" do Núcleo de Estudos e Pesquisas sobre Etnicidade (NEPE) da Universidade Federal de Pernambuco.

Essas fotografias foram realizadas pelo pesquisador Carlos Estevão no ano de 1937 quando esteve nas terras Pankararu e quando iniciou seu trabalho etnográfico com esse povo. As fotos foram selecionadas para mostrar a relação dos Pankararu com a dimensão do sagrado, a relação que eles têm com as forças encantadas nas aldeias onde vivem, nos municípios de Tacaratu, Jatobá e Petrolândia, no sertão do sub médio Rio São Francisco.

Os Encantados são entidades que fazem parte da cosmologia Pankararu. Eles estão presentes em toda a terra indígena e agem como intermediários entre aqueles que estão na Terra, que fazem parte do mundo humano, com a entidade maior - que não está presente nessa Terra. Essa relação se efetua em diversos momentos num calendário rico e dinâmico nos "terreiros" (lugar público onde o sagrado estabelece relação com as pessoas desse mundo) das diversas aldeias Pankararu. Nesses terreiros, os "Praiás" - entes que têm um nome próprio, devidamente vestidos em 
trajes feito exclusivamente da fibra do "caroá" - manifestam-se publicamente para as pessoas presentes. O Praiá é um personagem mitológico que se encantou e que se tornou um intermediário das forças vitais para a movimentação e a dinâmica ritualística do mundo Pankararu. Esses encantados vão estar presentes nas festas e cerimônias rituais dos Pankararu durante o ano.

A mais importante manifestação religiosa Pankararu é as "Corridas do Umbu", quando o ano começa, depois das trovoadas de janeiro, com as plantações sendo iniciadas após as primeiras chuvas. Com o aparecimento do "imbu", como eles dizem, os detentores de saber vão escolher o dia para o "flechamento" do primeiro umbu que aparece, e, no final de semana seguinte, iniciam-se as corridas que vão ser movimentadas em dois principais terreiros: o do Brejo dos Padres e o da Serrinha. Durante quatro finais de semana, os Pankararu se ajuntam nesses terreiros para dançar os torés, queimarem-se com as urtigas de cansanção e, sobretudo, para buscarem a força encantada para o ano. Essa festa se inicia na madrugada do sábado, tanto na Serrinha quanto no Brejo, com a lembrança de todas as possibilidades de vida e a dança de humanos e animais em um conjunto coreográfico imponente, em que os Praiás, por meio de um ritmo contagiante e alegre, vão relatando as forças e as belezas dos animais e a relação entre humanos e não humanos nesse mundo presente. Essa festa termina no quarto final de semana, com a saída do "Mestre Guia", chefe de todos os encantados. A saída do Mestre Guia, no terreiro apropriado - na Serrinha -, é vista por todos que se identificam com parte da identidade Pankararu com muita consternação. Ele é recebido com muita alegria em uma cerimônia em que o silêncio é parte fundamental para o recebimento dessa força.

As outras festas entre os Pankararu são realizadas em um calendário que não é fixo. o ritual do "Menino-no-Rancho" é uma manifestação em que todos os Pankararu são chamados para participar. Envolve um considerável trabalho de logística e de organização. Tem um caráter de iniciação e representa a proclamação pública de uma clara intervenção de um encantado em um menino. Os pais do menino precisam organizar esse ritual - que dura pelo menos uma noite e um dia completo. Os pais do menino precisam, também, buscar uma quantidade muito grande de comida para oferecer a todos os convidados que, às vezes, ultrapassam 500 pessoas. Os pais do menino convidam uma noiva e duas madrinhas para ele, e também vão arregimentar o maior número de padrinhos possível. A noiva vai dançar com o menino acompanhado pelas duas madrinhas. Os padrinhos vão ter um papel importante no momento da luta com os pais, para garantir que o menino possa ficar nesse mundo. Uma luta entre os céus e a terra, em que o menino será guardado pelos padrinhos. Essa luta pode durar uma tarde inteira. Ao término, o menino será enfim guardado por um dos Praiás, que passará a protegê-lo por toda a vida. 


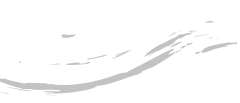

As outras festas são organizadas por famílias zeladoras de Praiás, pois cada uma delas possui um número de certo desses entes encantados. Essas famílias organizam os espaços (Poró) onde os Praiás são guardados e onde certas obrigações são realizadas de forma a manter a força encantada viva entre os membros da família. Em todas as obrigações estão

texto recebido

08.06.2016

texto aprovado

31.08.2016 presente as ervas, o fumo encantado (tabaco aromatizado de preparo exclusivo para as forças encantadas) e o vinho de ajucá (bebida preparada da jurema). Esses vegetais são um sinal do respeito ao sagrado, pois são vistos como elementos de sustentação do mundo em que vivemos.

\section{RENATO ATHIAS}

Doutor em Antropologia pela Universidade de Paris X - (Nanterre), Professor Associado do Departamento de Antropologia e Museologia, docente do Programa de Pós-Graduação em Antropologia da Universidade Federal de Pernambuco, onde também coordena o Laboratório de Antropologia Visual e o Núcleo de Estudos e Pesquisas sobre Etnicidade (NEPE).

\section{SARAPÓ PANKARARU}

Líder Pankararu da Aldeia Brejo dos Padres da Terra Indígena Pankararu, coordenador da "Casa de Memória do Tronco Velho Pankararu" e coordenador da APOINME. 